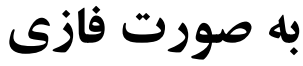

\author{
مهرداد روحانى '، حسن فرسى '، سيد حميد ظهيرى ممقانى \\ ' دانشجوى د كترى مهندسى برق، گروه مخابرات، دانشگاه بير جند، M.ruhani@birjand.ac.ir

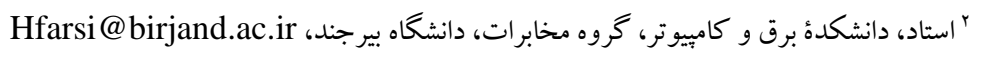

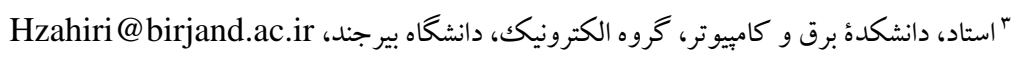

$$
\begin{aligned}
& \text { جكيده: امروزه يكى از اساسى ترين فر آيندها به منظور ادراكك محتواى ويديو، رديابى اشيا متحرك است كه در آن فر آيند مكانيابى } \\
& \text { شى متحر ك،، در هر فريم از ويدئو صورت مى گيرد. در يكك فر آيند رديابى لازم است، هدف توسط يكك ويزگى توصيف شود. در اين مقاله } \\
& \text { بهنظور توصيف شى متحر كك و رفع حساسيت به ظاهر هدف، از هيستو گرام وزندار رنگك به بنوان ويزگى هدف متحر كى استفاده شده است } \\
& \text { تا اثر ييكسل هاى لبهى شى هدف در ويزگى آن كاهش داده شود. اين كار حساسيت الكوريتم را به تغيير حالت، تغيير مقياس و جرخش } \\
& \text { كاهش داده و اثر انسداد جزيى بر توصيف ويزگى هدف متحرك نيز كاهش مى يابد. در روش بيشنهادى، از الكوريتم بهينهسازى ازدحام } \\
& \text { ذرات به صورت فازى شده در فر آيند جستجوى هدف استفاده مىشود. نحوه تعيين موقعيت هدف براساس بيشينه شدن تابع شباهت و محاسبه } \\
& \text { كمترين فاصله باتاجاريا است. بِارامترهاى كنترلى فازى شده براى الكوريتم بهينهسازى ازدحام ذرات استفاده شده است كه يك روش نوين } \\
& \text { را ارائه مى كند، اين كار مىتو اند هر بارامتر كنترلى رابه موقع و طبق حالات مختلف هر ذره در هر نسل تنظيم و به روزرسانى كند. الكوريتم } \\
& \text { ازدحام ذرات اصلاح شده توسط ال تابع محكك مورد ارزيابى قرار گرفته است. آزمايشها نشان مىدهند كه الخوريتم اصلاح شده در تعداد }
\end{aligned}
$$

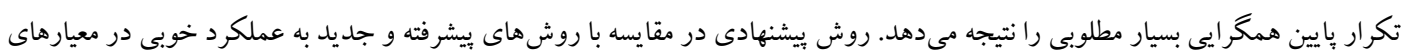

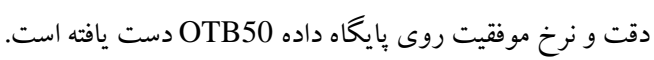$$
\text { كلمات كليدى: رديابى شى متحرك، الخوريتم بهينه سازى ازدحام ذرات اصلاح شده، ويز گى هيستو گرام رنكى وزندار. }
$$

\section{Moving object tracking in video by using fuzzy particle swarm optimization algorithm}

\section{Mehrdad Rohani, Hasan Farsi, Seyedhamid Zahirimamaghani}

\begin{abstract}
Nowadays, one of the most fundamental processes for realization video of contents is the object tracking, in which the process of location the moving object is performed in each video frame. In tracking process, the target must be described by a feature. In this paper, for the purpose of describing the target and removing the appearance sensitivity, the weighted color histogram is used as a target feature in order to reduce the effect of edge pixels on the target feature. This reduces the sensitivity of the algorithm to change deformation, scale variation and rotation, as well as the occlusion on the description of target feature. In the proposed method, particle swarm optimization algorithm has been used for search process. Maximization of the similarity function and calculating the minimum Bhattacharyya distance are used to determine target location. The fuzzy control parameters are used for the particle swarm optimization algorithm, which provides a novel method, which can regulate each control parameter and update according to the different states of each particle
\end{abstract}




$$
\begin{aligned}
& \text { رديابى شى متحرك دى ويديو با استفاده از الكوريتم بهينه سازى ذرات به صورت فازى } \\
& \text { مهرداد روحانى، حسن فرسى، سيد حميد ظهيرى ممقانى }
\end{aligned}
$$

in each generation. The improved particle swarm algorithm is evaluated with 11 benchmark functions. The obtained results by improved algorithm show that appropriate convergence in a low number of iterations. The proposed method compared to state-of-the-art methods provides high performance in the success and precision rate on the OTB50 dataset.

Keywords: Object tracking, Improved particle swarm optimization algorithm, Weighted color histogram feature.

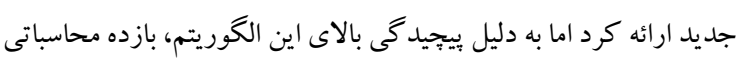

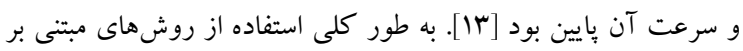

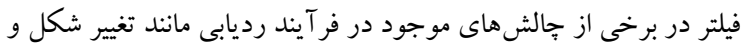

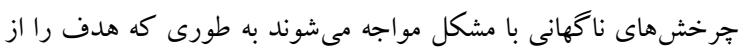
دست داده و در برخى موارد قادر به بازيابى آن نيستند.

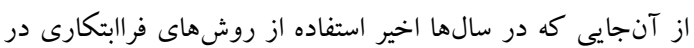

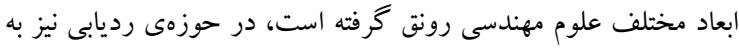
عنوان دستهى ديخرى از روشها، از الكوريتمهاى فرابتكارى استفاده شده دئه

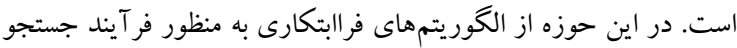

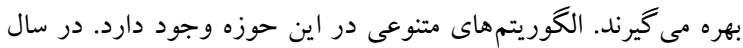

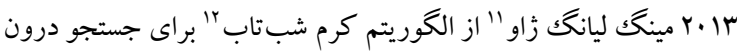

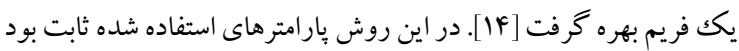

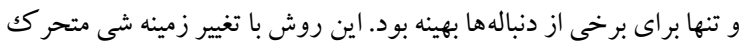

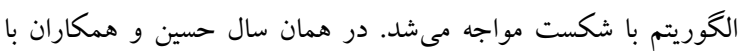

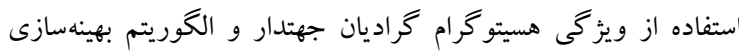

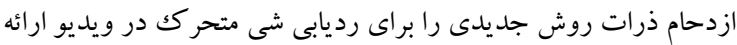

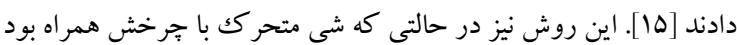

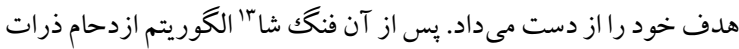

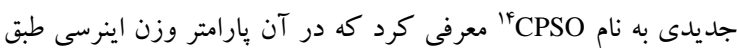

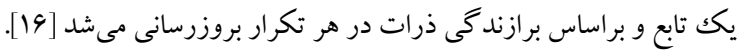

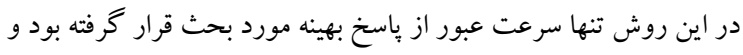

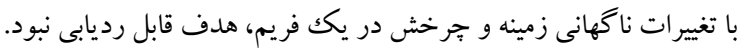

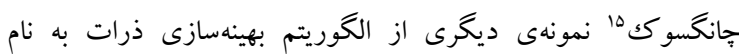

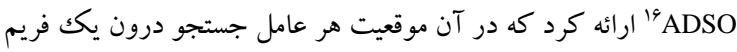

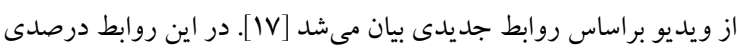

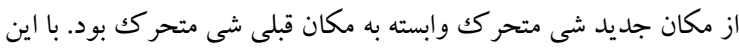

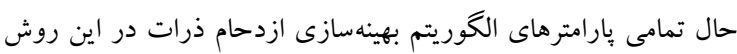

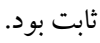

- 1

در سالهاى اخير فناورى رديابى اشيا موضوع مهمى در بينايى ماشينى

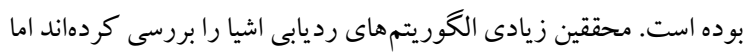

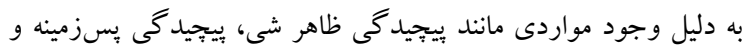

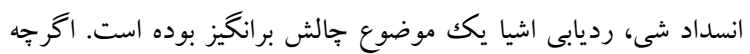

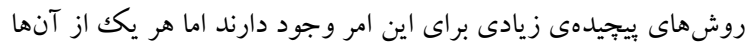

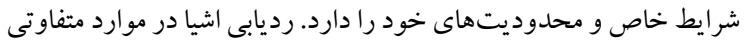

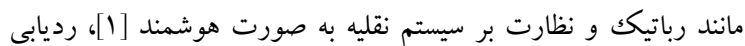

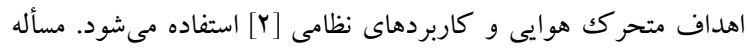

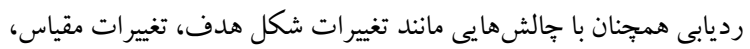

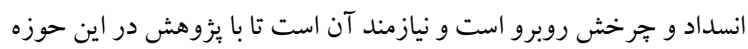

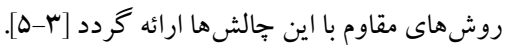
تاكنون روش هاى متنوعى در حوزه رديابى در ويديو مطرح گرديده

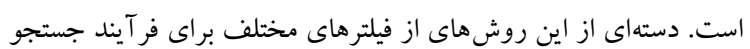

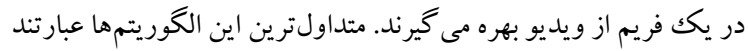

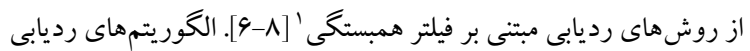

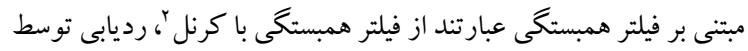

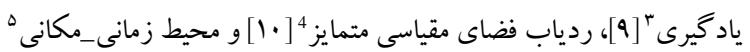
[11]. به طور كلى، قائدهى جستجوى هدف متحرك دك در استفاده از فيلتر

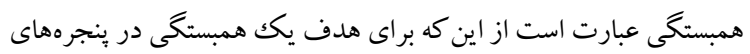

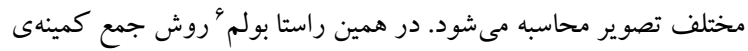

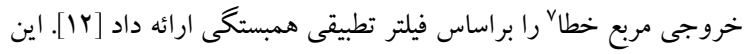

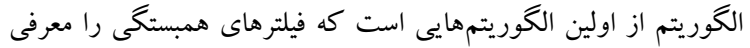

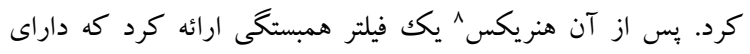

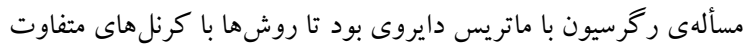

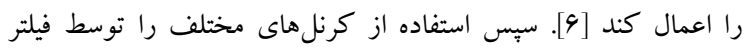
همبستخى بهبود بخشيد [V]]. مارتين و ويز گیىهاى سياه سفيد در الكوريتم

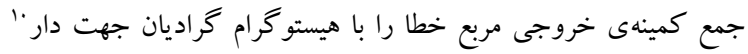

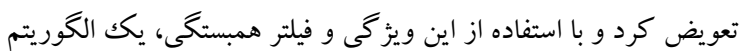

\begin{tabular}{ll}
\hline${ }^{10}$ Histogram of Gradient & ${ }^{1}$ Correlation Filtering \\
${ }^{11}$ Ming-Liang Gao & ${ }^{2}$ Kernelized Correlation Filter \\
${ }^{12}$ Firefly & ${ }^{3}$ Tracking-Learning-Detection \\
${ }^{13}$ Feng Sha & ${ }^{4}$ Discriminative Scale Space Tracker \\
${ }^{14}$ Categorized Particle Swarm Optimization & ${ }^{5}$ Spatio-Temperal Context \\
${ }^{15}$ Changseok & ${ }^{6}$ Bolme \\
${ }^{16}$ Adaptive Discrete Swarm Optimization & ${ }^{7}$ Minimum Output Sum of Squared Error \\
& ${ }^{8}$ Henriques \\
\hline
\end{tabular}


جواب را تغيير مىدهند در حالى كه روشهاى مبتى بر جمعيت در حين

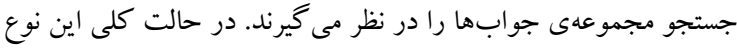

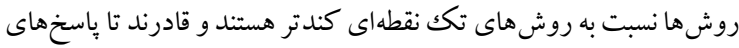

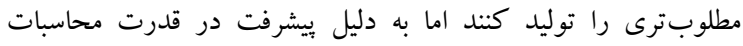
كاميوترى روش هاى مبتنى بر جمعيت داراى اهميت بالاترى هستند كه از

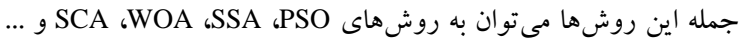

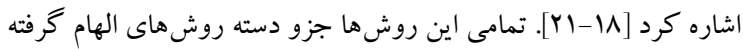
از طبيعت هستند. شكل ا دستهبندى الكوريتمهاى فرابتكارى را نمايش رون

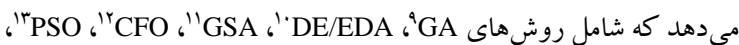
مي و

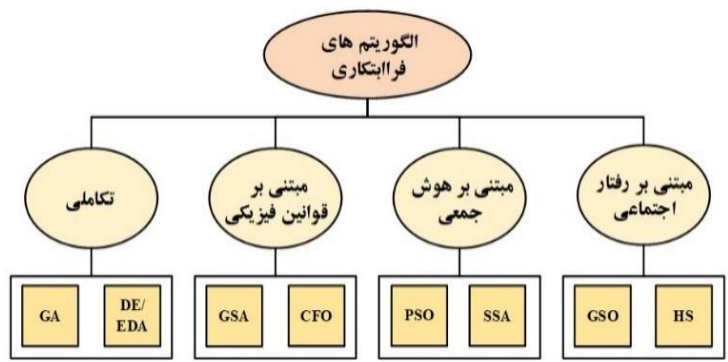

شكل ا: دستهبندى الكوريتمهاى تكاملى [r.].

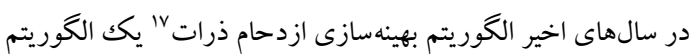
بهينهسازى بسيار بر كاربرد در حوزه بهينه سازى بوده است. بسيارى اين

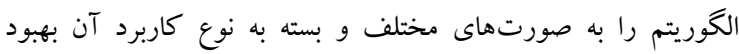

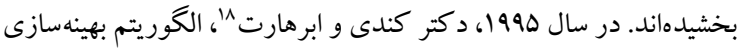
ازدحام ذرات را براى بهينهسازى توابع غيرخطى ارائه دادند. اين الكوريتم

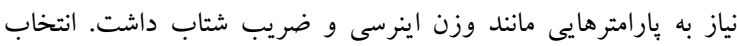

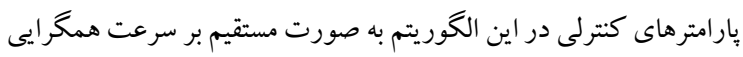

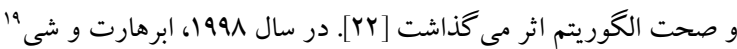

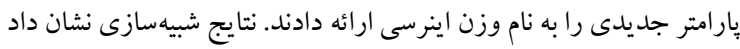

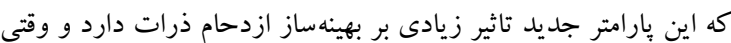

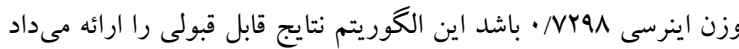

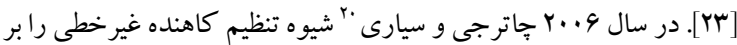
طبق تعداد تكرارها، براى تنظيم وزن اينرسى معرفى كردند. اين شيوه اجازه

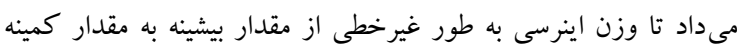

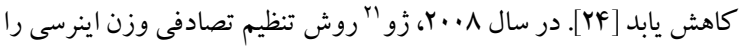

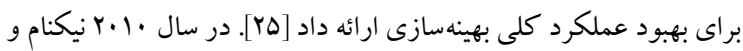

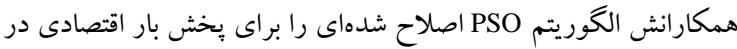
سيستمها قدرت معرفى كرد كه در آن بارامترهاى كنترلى
به طور كلى تا كنون روش هاى متعددى براى رديابى يكك شى متحر كك

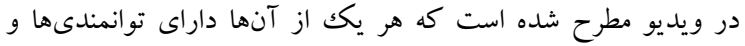
ضعفهاى متفاوتى هستند. الكوريتم بهينهازى ازدحام ذرات يكى از از سريعترين و سادهترين الكوريتمهايى است كه در حوزه الكوريتمهاى

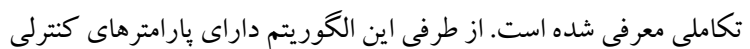

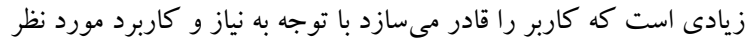
اين بارامترها را تغيير دهد. از آنجايى كه ماهيت رديابى شى متحر كك نياز

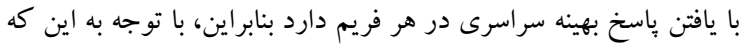

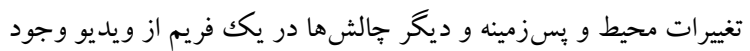
دارد و همجنين با توجه به ثابت بودن بارامترهاى كنترلى در الكوريتم

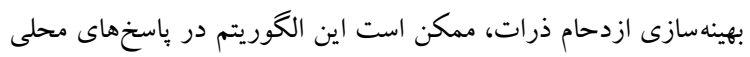

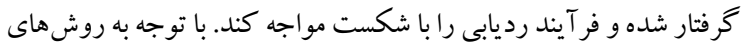

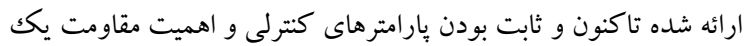

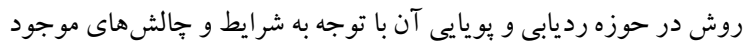

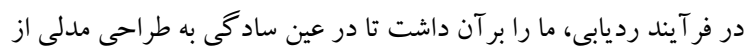

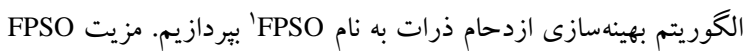
نسبت ساير مدلهاى ارائه شده در بهينه بودن بارامترهاى كنترلى در كل بلى

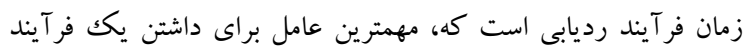

$$
\text { رديابى موفق و مقاوم است. }
$$

\section{r- التوريتم PSO فازى شده پيشنهادى}

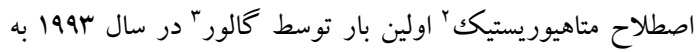

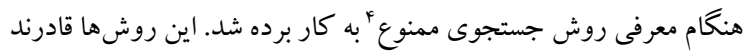

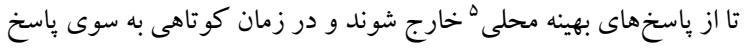

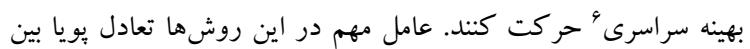

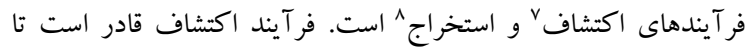

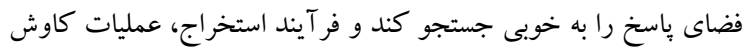

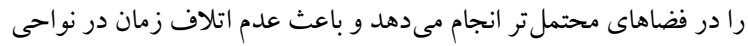

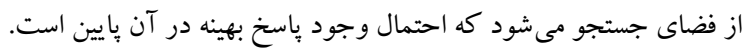

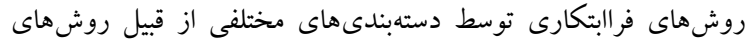

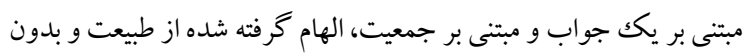

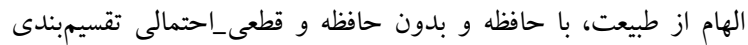

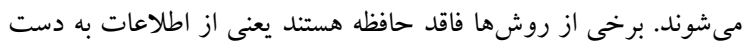

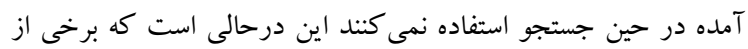
روشهاى فرابتكارى از اطلاعات به دست آمده در حين جستجو بهره

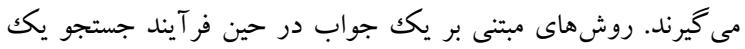

\footnotetext{
${ }^{12}$ Central Force Optimization

${ }^{13}$ Particle Swarm Optimization

${ }^{14}$ Salp Swarm Optimization

${ }^{15}$ Glowworm Swarm Optimization

${ }^{16}$ Harmony Search

${ }^{17}$ Particle Swarm Optimization

${ }^{18}$ Kennedy and Eberhart

${ }^{19}$ Shi and Eberhart

${ }^{20}$ Chatterjee and Siarr

${ }^{21} \mathrm{Zhu}$
}

\author{
Fuzzy Particle Swarm Optimization \\ ${ }^{2}$ Metahuristic \\ ${ }^{3}$ Golver \\ ${ }^{4}$ Tabu search \\ ${ }^{5}$ Local \\ ${ }^{6}$ Global \\ ${ }^{7}$ Exploration \\ ${ }^{8}$ Exploitation \\ ${ }^{9}$ Genetic Algorithm \\ ${ }^{10}$ Differential Evolution/Estimation of Distribution Algorithm \\ ${ }^{11}$ Gravitational Search Algorithm
}


است كه ذرات به سمت باسخ بهينه ميل مى كند. ذرات از يكديخر

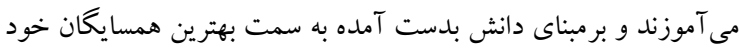

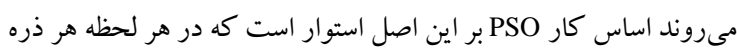

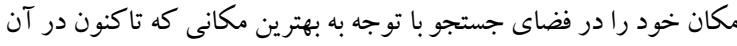

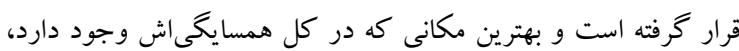
تظظيم مى كند. در فضاى n بعدى هر ذره داراى يكك موقعيت است كه توسط بردار ix به صورت زير مشخص مى گر درد [11]]. $x_{i}=\left(x_{i 1}, x_{i 2}, \ldots, x_{i n}\right)$

كه در آن

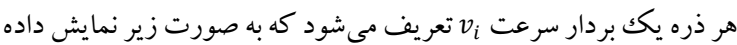

$v_{i}=\left(v_{i 1}, v_{i 2}, \ldots, v_{i n}\right)$

كه در آن

بهترين موقعيت P..best در هر بعد به صورت زير نشان داده مى شود.

$P_{\text {i.best }}=\left(p_{i 1}, p_{i 2}, \ldots, p_{i n}\right)$

كه در آن

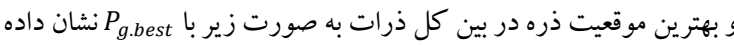

مىشود.

$P_{\text {g.best }}=\left(p_{g 1}, p_{g 2}, \ldots, p_{g n}\right)$

سرعت و مكان هر ذره در هر تكرار با استفاده از روابط (1) و (Y) (Y)

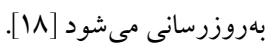

$V_{i}(t)=w * V_{i}(t-1)+C_{1} * \operatorname{rand}_{1} *\left(P_{i, b e s t}-\right.$

$\left.X_{i}(t-1)\right)+C_{2} * \operatorname{rand}_{2} *\left(P_{i, g, b e s t}-X_{i}(t-1)\right)$

$$
X_{i}(t)=X_{i}(t-1)+V_{i}(t)
$$

در روابط (1) و (Y)، Popsize ذرات (عوامل جستجو) را بيان مى كند. w ضريب وزنى اينرسى (حركت

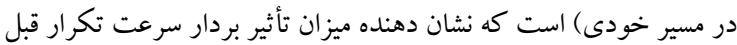
م $V_{i}(t-1)$

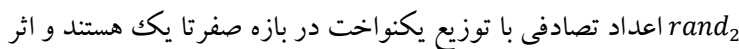
تصادفى بودن را در حركت فردى و گروهى ذرات ايجاد مى كنند.

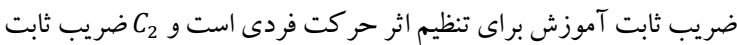

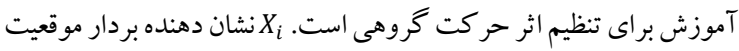
هر ذره مىباشد. ضرايب w w

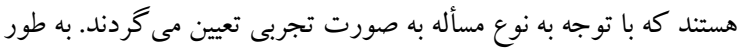

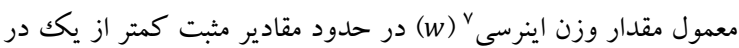

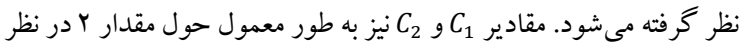

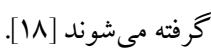

صورت فازى كنترل مى شدند [4؟]. تفاوت روش بيشنهادى با اين روش در نوع و تعداد ورودى و خروجى هاى سيستم فازى و نحوه تعريف توابع عضويت است كه روش بيشنهادى از تعداد خروجىهاى بالاتر و و

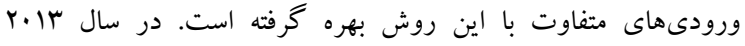

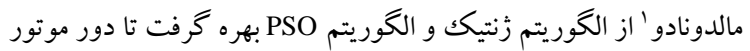

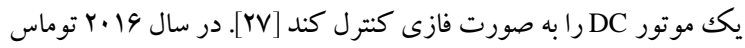

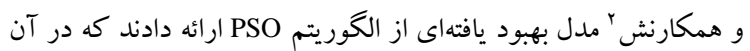

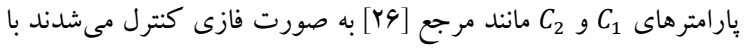

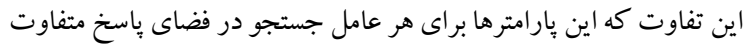

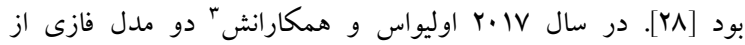

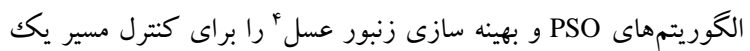

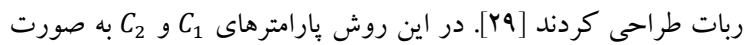

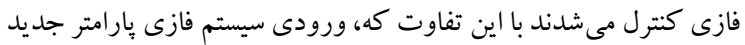
بود كه مشخص مى كرد جه تعداد از عوامل جستجو نزديكك هم هستند و

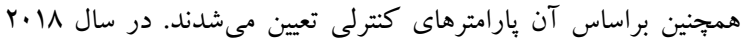

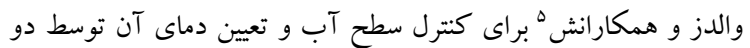

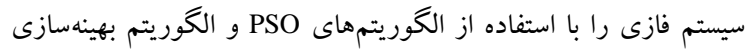

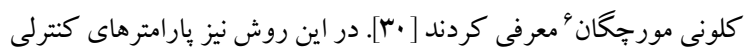
PSO به صورت فازى كنترل مىشدند. در اين

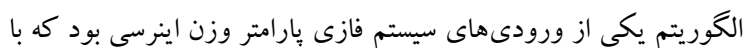

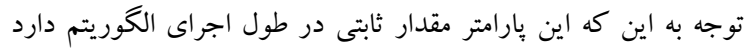

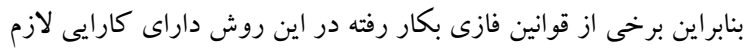
نبودند. تاكنون روشهاى متنوعى براى فازى كردن الكوريتم PSO معرفى

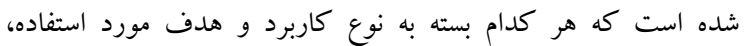
بارامترهاى كنترلى موجود در الكوريتم را مورد تغيير و بررسى قرار دادهاند. روش بيشنهادى معرفى شده علاوه بر بارامترهاى

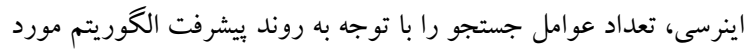

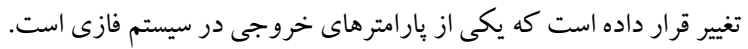

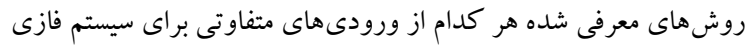

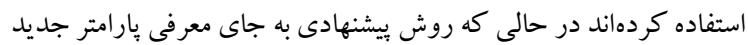

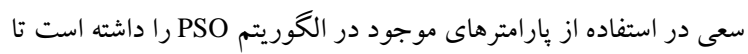

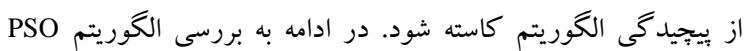
متداول و روش ييشنهادى يرداخته شده است.

\section{| - 1 - معرفى الكوريتم PSO متداول}

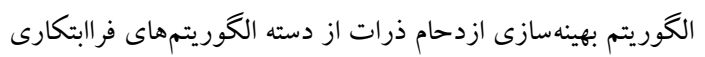

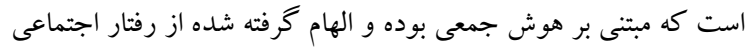

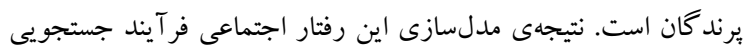

$\begin{array}{ll}{ }^{5} \text { Valdez et al } & { }^{1} \text { Maldonado } \\ { }^{6} \text { Ant Colony Optimization } & { }^{2} \text { Tomasz et al } \\ { }^{7} \text { Inertia weight } & { }^{3} \text { Olivas et al } \\ & { }^{4} \text { Bee Colony Optimization }\end{array}$


محلى همخرا شود. در بسيارى از يُزوهشها براساس تاثير بالاى وزن بر

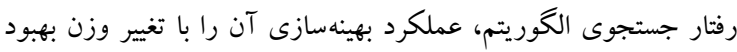
بخشيدهاند. درحال حاضر، روش هاى بهبود يافتهاى براى تنظيم وزن اروائه شده است كه مى تو ان به انتخاب تصادفى وزن به جاى مقدار ثابت، انتخاب

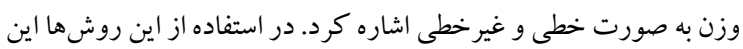

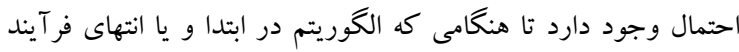
جستجو در يكك نقطه بهينه محلى قرار گرفته است، در همان نقطه گرفتار

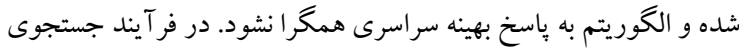

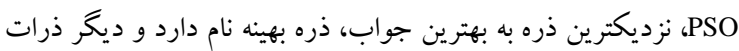

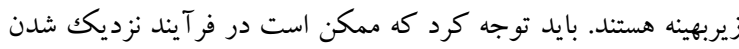

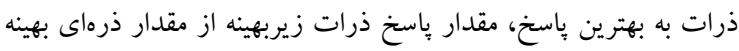

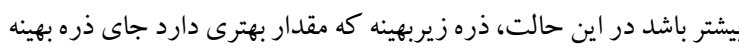

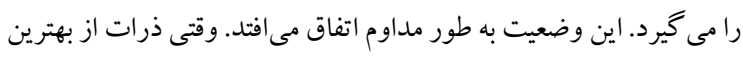

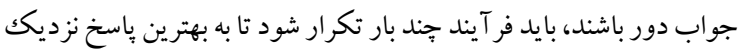

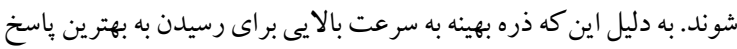

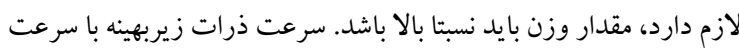

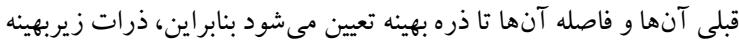

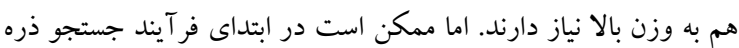

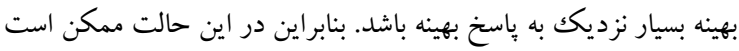

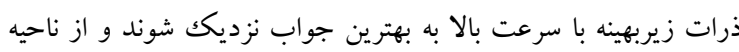
بهترين ياسخ با سرعت عبور كنند كه اين امر سبب مىشود كه ذرات وارد

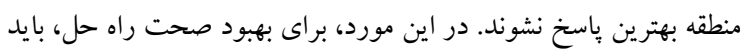

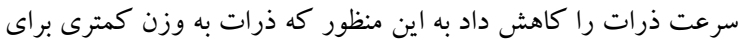

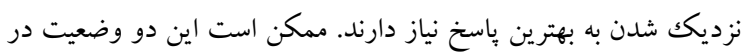

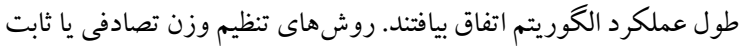

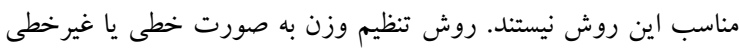

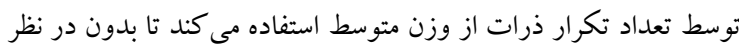

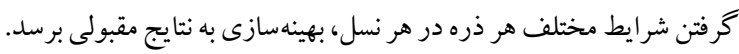

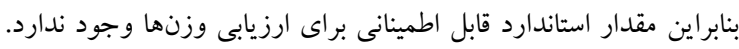

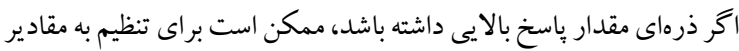

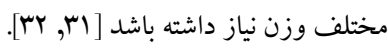
تعداد ذرات (Popsize) در الكوريتم PSO با توجه به نوع مسأله تعيين مىشود. اين سوال مطرح مىشود كه اندازه جمعيت ثابت در زمان اجرا

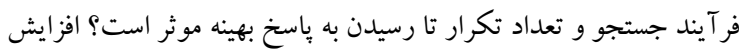

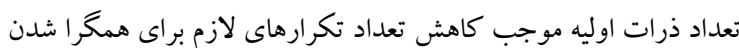
الكوريتم مى گردد زيرا فضاى جستجو با افزايش جمعيت بيشتر يوشش دائ داده

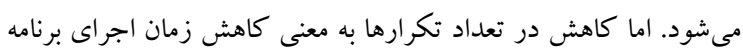

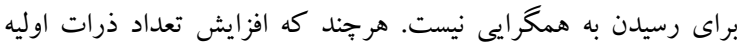

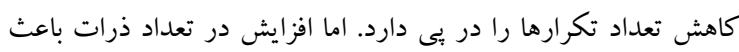

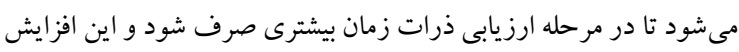

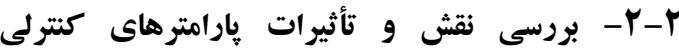

PSO الكوريتم

بارامترهاى كنترلى همخرا شدن دارند. فردى هر عامل جستجو در فضاى جستجو است. نحوه عملكرد آن بستخى

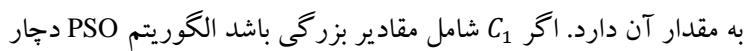

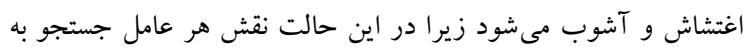

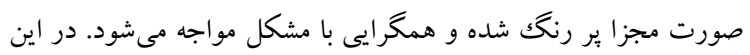

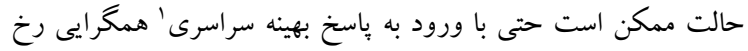

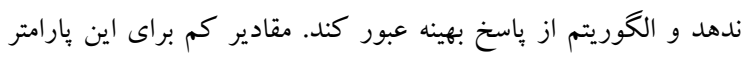

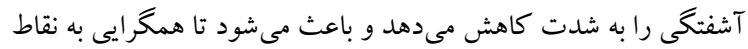

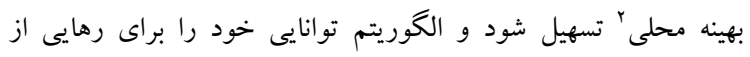

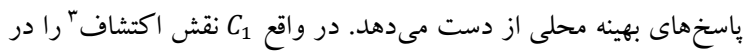

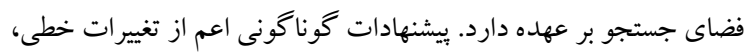
انتخاب تصادفى و يا تغييرات غير خطى براى اين پارامتر ارائه شده است.

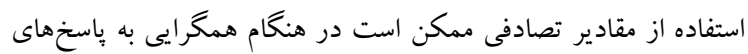

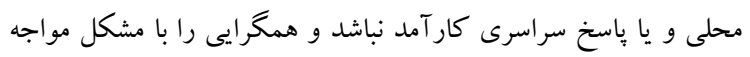

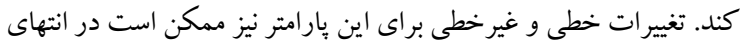

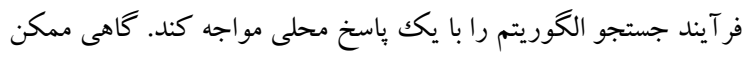
است در ابتداى فر آيند جستجو و توليد جمعيت اوليه تصادفى، الكوريتم

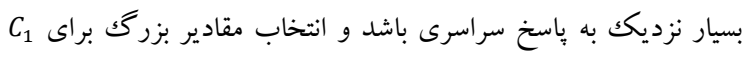

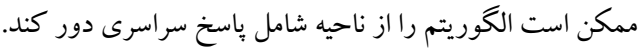

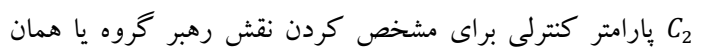
بهترين رفتار اجتماعى است. مقادير كو جكك براى اين بارامتر نقش بهترين

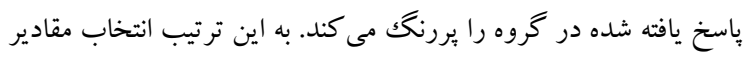

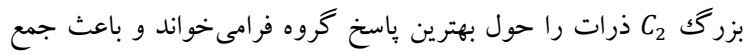

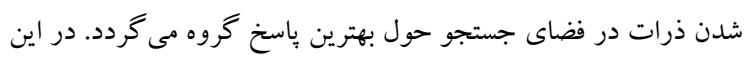

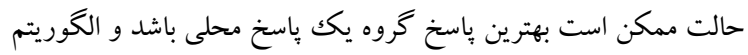

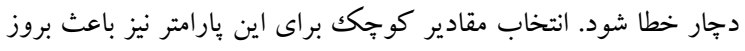

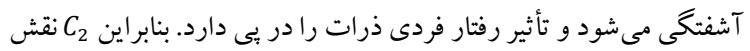

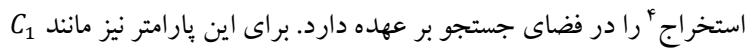

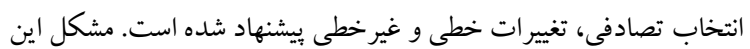

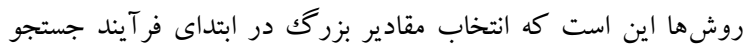

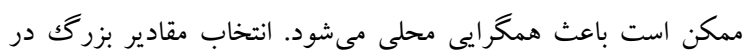

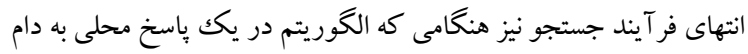
افتاده است، باعث همخر ايى محلى مى گردد.

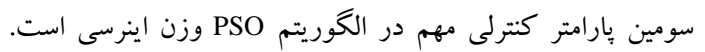

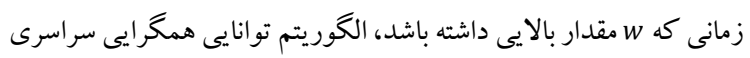
بالايى دارد، درحالى كه وزن كم باعث مىشود تا الكوريتم به نقاط بهينه

\begin{tabular}{ll}
\hline${ }^{3}$ Exploration & ${ }^{1}$ Global \\
${ }^{4}$ Exploitation & ${ }^{2}$ Local \\
\hline
\end{tabular}


تكرار جارى و خروجى آن ضرايب wo w و و توجه به تغييرات بهترين باسخ و تكرار جارى براى بالا بردن دقت و سرعت

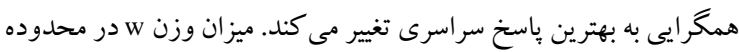

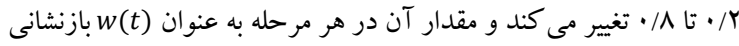

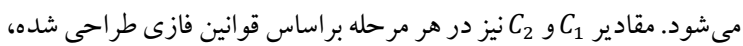

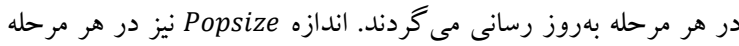

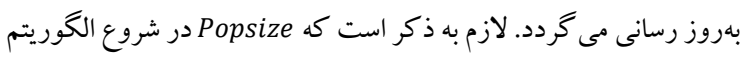
مقدار داده مىشود و ميزان آن بين مقدار اوليه و صفر تغيير مى كند. درد

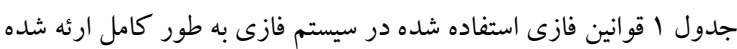

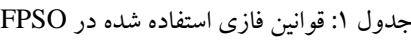

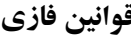

1. If (Fbest is High) and (Iteration is Low) then (C1 is High)(C2 is Low)(W is High)(Popsize is High)

2. If (Fbest is High) and (Iteration is Median) then (C1 is High)(C2 is Low)(W is High)(Popsize is High)

3. If (Fbest is High) and (Iteration is High) then (C1 is High)(C2 is Median)(W is Median)(Popsize is High)

4. If (Fbest is Median) and (Iteration is Low) then (C1 is High)(C2 is Low)(W is High)(Popsize is High)

5. If (Fbest is Median) and (Iteration is Median) then (C1 is High (C2 is Low)(W is Median)(Popsize is High)

6. If (Fbest is Median) and (Iteration is High) then (C1 is High)(C2 is Median)(W is Median)(Popsize is High)

7. If (Fbest is Low) and (Iteration is Low) then (C1 is Median)(C2 is High)(W is Low)(Popsize is High)

8. If (Fbest is Low) and (Iteration is Median) then (C1 is Low)(CZ is High)(W is Low)(Popsize is Median)

9. If (Fbest is Low) and (Iteration is High) then (C1 is Low)(C2 is High)(W is Low) (Popsize is Median)

\section{r- نحوه استفاده از روش FPSO در مسأله رديابى هدف متحر كى}

به منظور به كارگيرى روش بيشنهادى در حوزه رديابى هدف

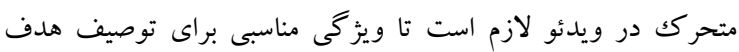

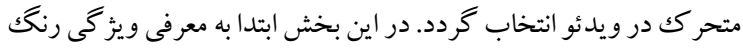

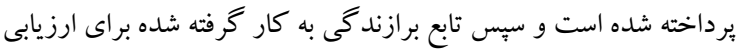

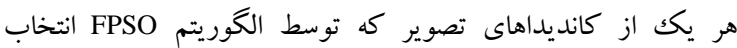
مىشوند، معرفى شده است.
در زمان ارزيابى سبب افزايش زمان اجراى الكوريتم تا رسيدن به همخرايى

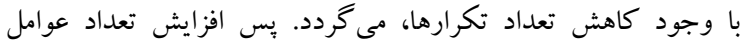

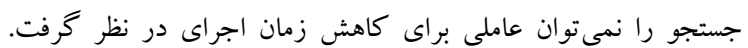
همجنين براى كاهش زمان اجر اي الخوريتم نمى توان تعداد عو امل جستجو

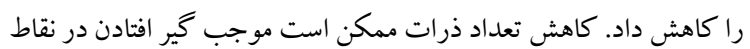

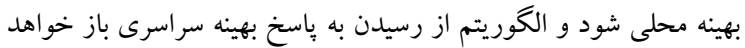

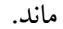

تعداد تكرار (t) بارامتر ديخرى است كه در زمان اجراى الكوريتم موثر است كاهش تعداد تكرار باعث كاهش زمان اجراى الكوريتم و

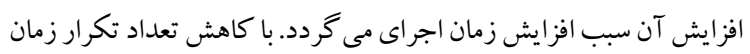

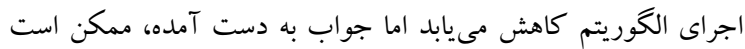

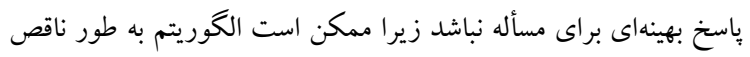

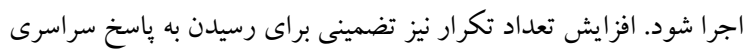

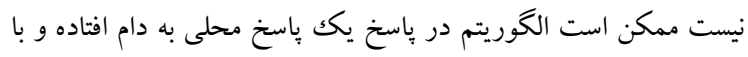
افزايش تكرار بيشرفتى در روند فر آيند جستجو حاصل نشود.

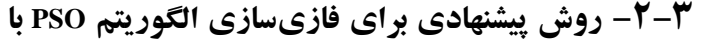 توجه به نقش یارامترهاى كنترلى آن}

براى حل مشكلهاى بيان شده، بايد يكك مصامحه بين بارامترهاى

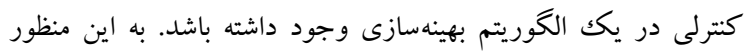
استفاده از روش هاى تصادفى، خطى و غيرخطى كارايى جندانى در رونى

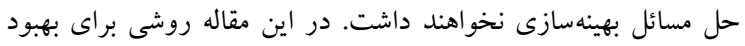

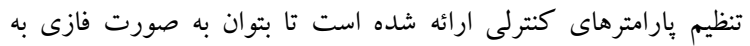

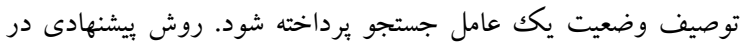

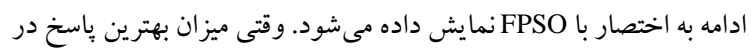

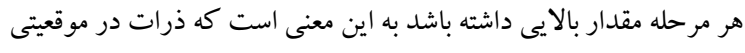
دور از بهترين ياسخ سراسرى به صورت خوشهاى جمع شدهاند و تمام

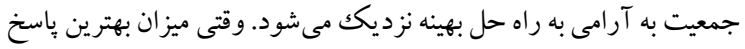

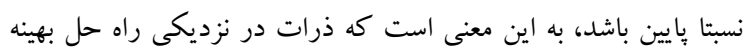

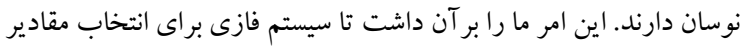

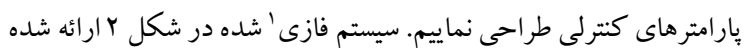
است كه در آن ورودى بهترين باسخ (Fbest) الكوريتم PSO و شماره

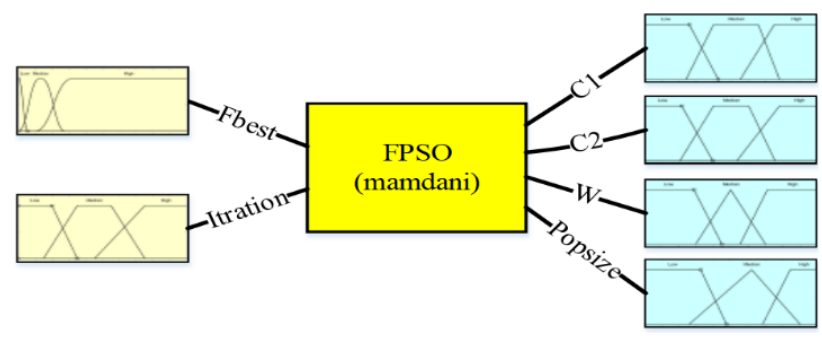

(الف)

${ }^{1}$ Fuzzy System 


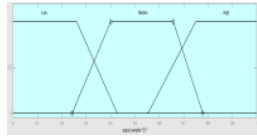

(ج)

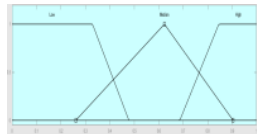

(د)

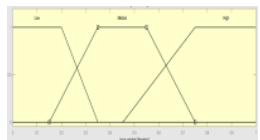

(ج)

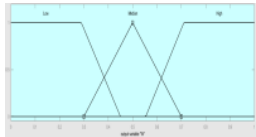

(خ)

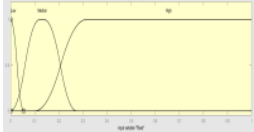

$(+)$

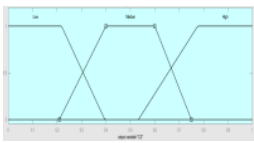

(ح)

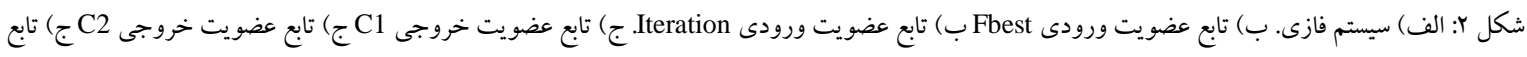
عضويت خروجى W ج ج ابع عضويت خروجى Popsize

با xx نمايش داده شده است، وزنهاى كمترى اختصاص مى مهد. زيرا اين

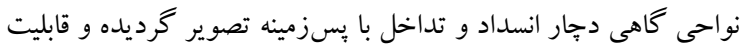

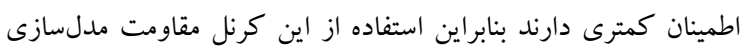

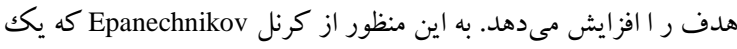

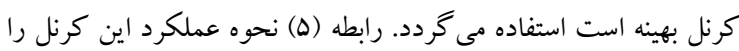

$$
\text { نمايش مى دهد. }
$$

$$
k_{E}(x)=\left\{\begin{array}{lr}
\frac{1}{2} c_{d}^{-1}(d+2)\left(1-\|x\|^{2}\right) & \text { if } \quad\|x\|<1 \\
0 & \text { otherwise }
\end{array}\right.
$$

در رابطه (ه)، d نمايانكر بعد فضا و d c براى ابعاد متفاوت مقادير مختلف

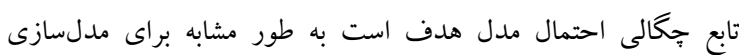
كانديداهاى مختلف در يكك فريم از

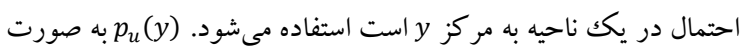

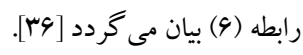

$$
p_{u}(y)=C_{h} \sum_{i=1}^{n} K\left(\left\|\frac{y-x_{i}}{h}\right\|^{2}\right) \delta\left[b\left(x_{i}\right)-u\right]
$$

در رابطه (9)، ينجره كرنل تعريف مى گردد و به صورت رابطه (V) نشان داده مى شود.

$$
C_{h}=\frac{1}{\sum_{i=1}^{n} K\left(\left\|\frac{y-x_{i}}{h}\right\|^{2}\right)}
$$

به منظور مدلسازى هدف و مدلسازى كانديداها در هر فريم از تابع

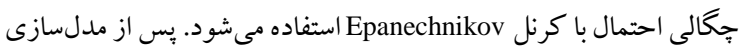
نياز است تا مدلهاى ارائه شده با يكديخر تطبيق يافته و مدلى كه بيشترين

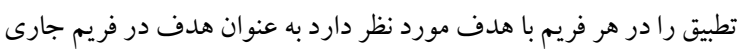

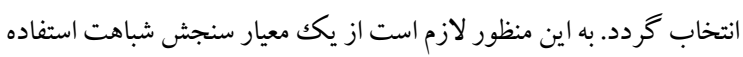
كردد كه در بخش معيار سنجش شباهت معرفى شده است.

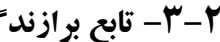

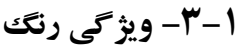

با معرفى هيستو گرام رنگك توسط سوين و بالارد' در سال 1991،

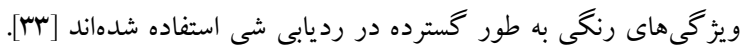

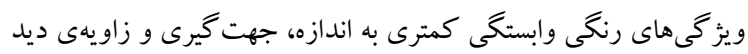
تصوير دارند، به همين دليل در توصيف يكك صحنه يا يك شكى شى تو انمندى

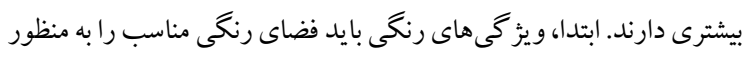

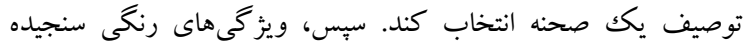

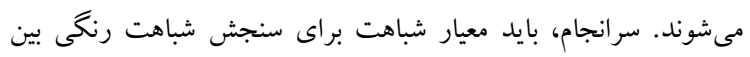

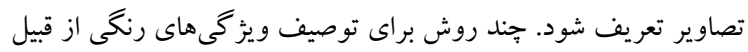

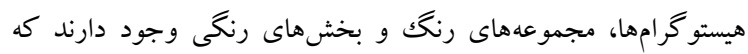

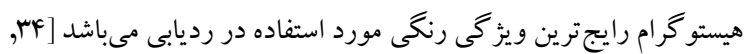

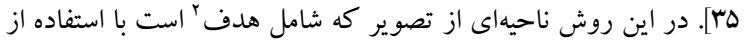

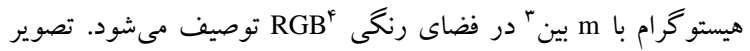

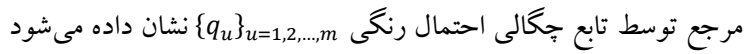

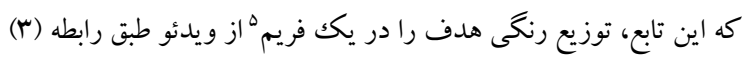

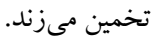

$$
q_{u}=C \sum_{i=1}^{n} K\left(\left\|\frac{x-x_{i}}{h}\right\|^{2}\right) \delta\left[b\left(x_{i}\right)-u\right]
$$
در رابطه (r) (r) هدف است.

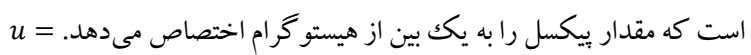

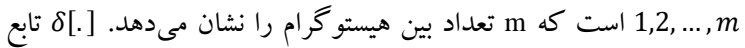

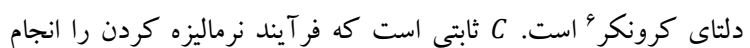
مىدهد تا شرط 1 مر

مى شود [1\%].

$$
C=\frac{1}{\sum_{i=1}^{n} K\left(\left\|\frac{x-x_{i}}{h}\right\|^{2}\right)}
$$

براى وزندهى از كرنل ايزوتروييكك (x) با ينجرهاى به شعاع

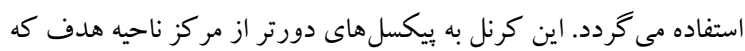

$\begin{array}{ll}{ }^{4} \text { Red-Green-Blue } & { }^{1} \text { Swain and Ballard } \\ { }^{5} \text { Frame } & { }^{2} \text { Target } \\ { }^{6} \text { Kronecker delta function } & { }^{3} \text { Bin }\end{array}$


توانمندى يكك روش را مورد تحليل قرار دهند. به منظور نشان دادن عملكرد

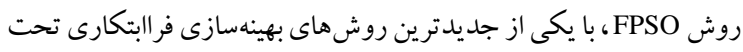

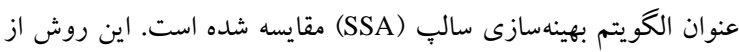

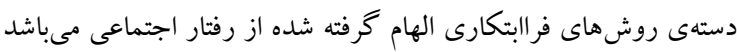

\begin{tabular}{|c|c|c|}
\hline \multicolumn{3}{|c|}{ جدول ז: توابع محكك } \\
\hline Function & Range & $f_{\min }$ \\
\hline$F_{1}(x)=\sum_{i=1}^{n} x_{i}^{2}$ & {$[-100,100]$} & 0 \\
\hline$F_{2}(x)=\sum_{i=1}^{n}\left|x_{i}\right|+\prod_{i=1}^{n}\left|x_{i}\right|$ & {$[-10,10]$} & 0 \\
\hline$F_{3}(x)=\sum_{i=1}^{n}\left(\sum_{j=1}^{i} x_{j}\right)^{2}$ & {$[-100,100]$} & 0 \\
\hline$\underset{n\}}{F_{4}(x)=\max _{i}\left\{\left|x_{i}\right|, 1 \leq i \leq\right.}$ & {$[-100,100]$} & 0 \\
\hline $\begin{array}{l}F_{5}(x)=\sum_{i=1}^{n-1}\left[100\left(x_{i+1}-\right.\right. \\
\left.\left.x_{i}^{2}\right)^{2}+\left(x_{i}-1\right)^{2}\right]\end{array}$ & {$[-30,30]$} & 0 \\
\hline$F_{6}(x)=\sum_{i=1}^{n}\left(\left[x_{i}+0.5\right]\right)^{2}$ & {$[-100,100]$} & 0 \\
\hline $\begin{array}{l}F_{7}(x)=\sum_{i=1}^{n} i x_{i}^{4}+ \\
\text { random }[0,1)\end{array}$ & {$[-1.28,1.28]$} & 0 \\
\hline$F_{8}(x)=\sum_{i=1}^{n}-x_{i} \sin \left(\sqrt{\left|x_{i}\right|}\right)$ & {$[-500,500]$} & $\begin{array}{l}-418.98 \\
\times 5\end{array}$ \\
\hline $\begin{array}{c}F_{9}(x)=\sum_{i=1}^{n}\left[x_{i}^{2}-\right. \\
\left.10 \cos \left(2 \pi x_{i}\right)+10\right]\end{array}$ & {$[-5.12,5.12]$} & 0 \\
\hline $\begin{array}{l}F_{10}(x)= \\
-20 \exp \left(-0.2 \sqrt{\frac{1}{n} \sum_{i=1}^{n} x_{i}^{2}}\right)- \\
\exp \left(\frac{1}{n} \sum_{i=1}^{n} \cos \left(2 \pi x_{i}\right)\right)+20+e\end{array}$ & {$[-32,32]$} & 0 \\
\hline $\begin{array}{l}F_{11}(x)=\frac{1}{4000} \sum_{i=1}^{n} x_{i}^{2}- \\
\prod_{i=1}^{n} \cos \left(\frac{x_{i}}{\sqrt{i}}\right)+1\end{array}$ & {$[-600,600]$} & 0 \\
\hline
\end{tabular}

نتايج حاصل شده از الكوريتم PSO فازى شده به FPSO نشان مىدهد كه اين روش به صورت قابل ملاحظهاى بيشرفت داشته است. شكل ع شامل r ستون است كه ستون اول رسم تو ابع محكك را در بازههاى استفاده شده

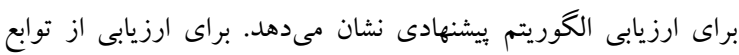

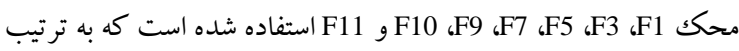

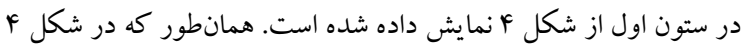

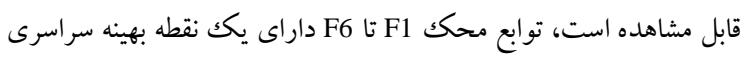
هستند در حالى كه توابع F7 تا F11 داراى تعداد زيادى نقطه بهينه محلى و

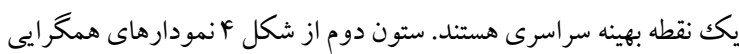

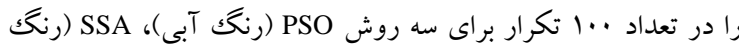

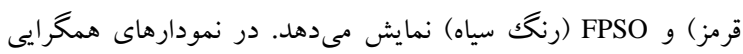
مشاهده مىشود كه، با اين كه روشهاى PSO و SSA به نقطه بهينه يعنى

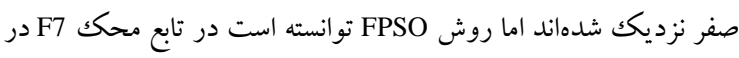
تعداد كمتر از •ه تكرار به باسخ بهينه سراسرى صفر برسد كه توانمندى

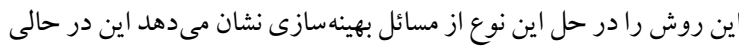

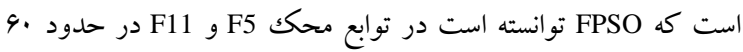

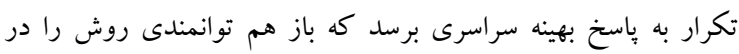

به منظور محاسيه برازندگى كانديداهاى موجود در يك تصوير و

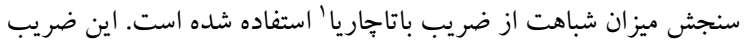

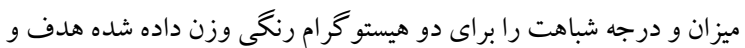

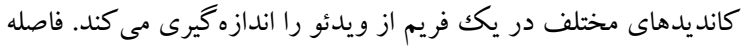

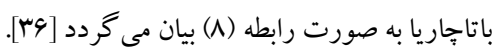

$$
\begin{aligned}
& d(y)=\sqrt{1-\rho[p(y), q]} \\
& \text { ضريب باتاجاريا در رابطه (A) مطابق با رابطه (9) بيان مى گردد. }
\end{aligned}
$$

$$
\rho[p(y), q]=\sum_{u=1}^{m} \sqrt{p_{u}(y), q_{u}}
$$

مقدارى بين صفر تا يكك دارد و زمانى كه مقدار $q$ براى $[p(y), q]$ هدف و p(y) براى يكك كانديد در يك فريم يك يكسان باشند

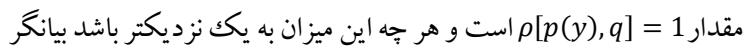

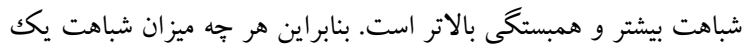

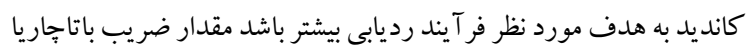

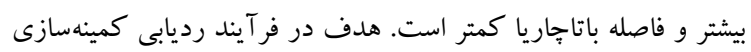
فاصله باتاجاريا مىباشد.

\section{ع- نتايج و ييشنهادات}

در اين قسمت ابتدا به معرفى توابع محكك براى ارزيابى روش FPSO

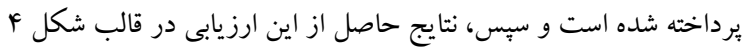

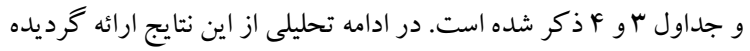

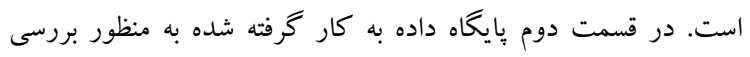

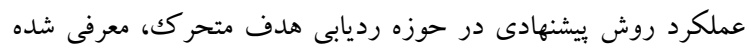
است. سبس، نتايج حاصل از اين روش بيشنهادى با وروش مرتبط و متداول

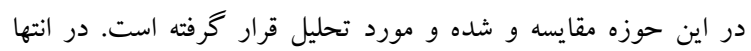
نتيجه گيرى و ييشنهادات روى اين تحقيق ارائه گرديده است.

ا - ع- توابع محكك

توابع محكك براى مسائل بهينهسازى به شكل كمينهساز مورد استفاده

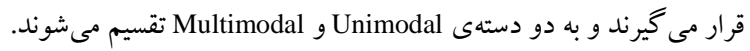
اين توابع در جدول ب ارائه شدهاند. Range، محدوده جستجو در فضاى

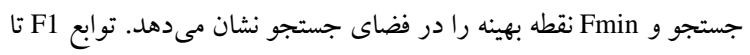

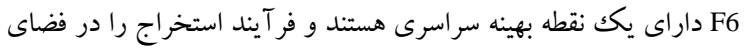

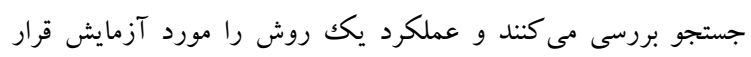

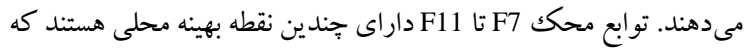
به طور نمايى با افزايش بعد افزايش مى يابند و به خوبى قادرند إندا فر آيند اكتشاف را در فضاى جستجو مورد آزمايش قرار دهند و شايستخى و

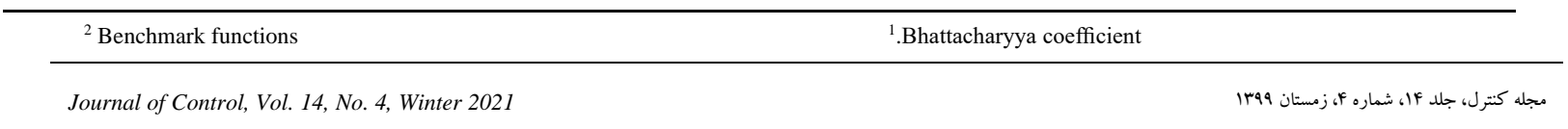




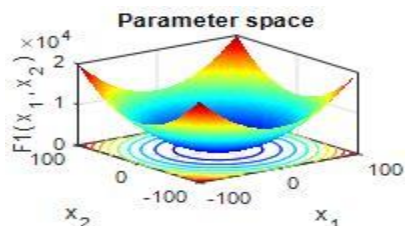

$x_{2}$ Parameter space
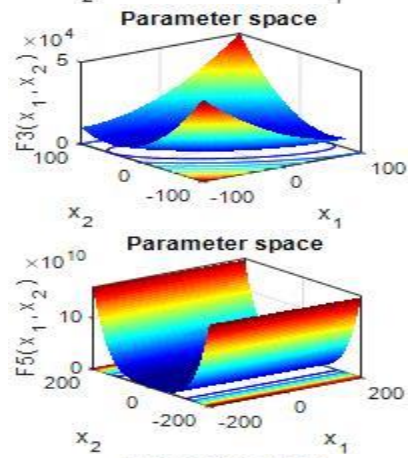

Parameter space

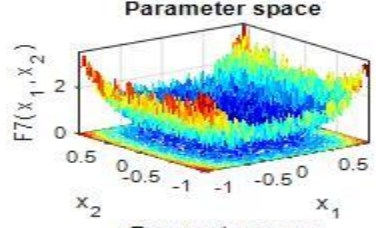

Parameter space

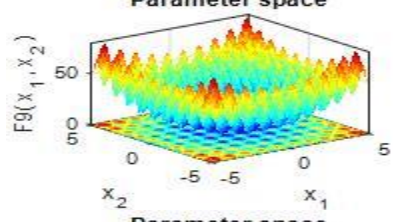

Parameter space

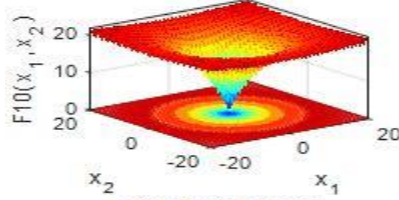

Parameter space

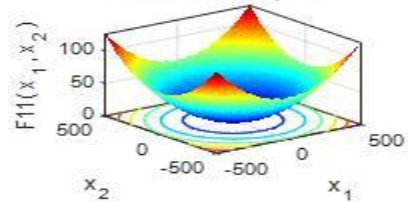

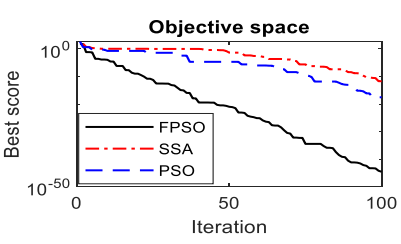

Iteration

Objective space
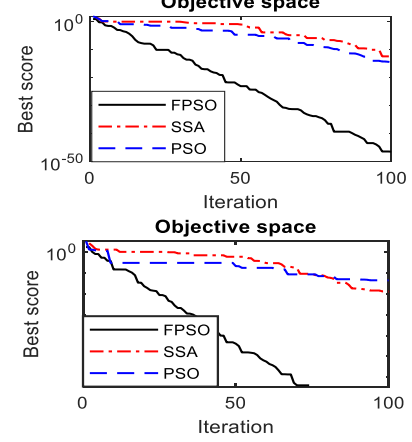

Objective space
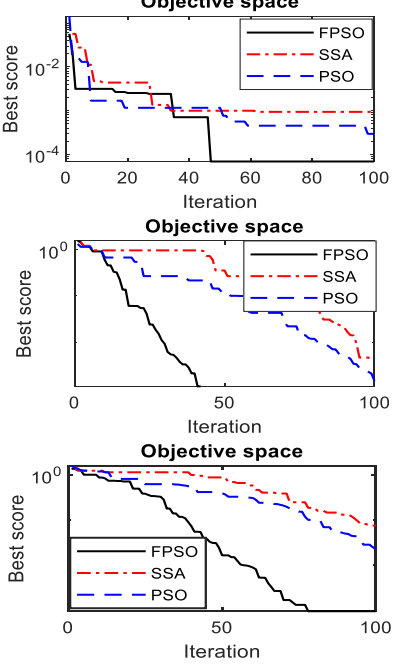

Objective space

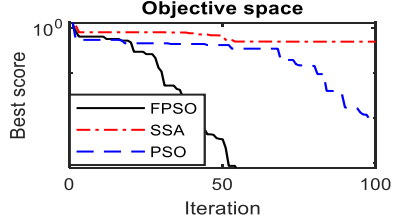

شكل \&: توابع محك و نمو دار همخرايى براى سه روش PSO، SSA و FPSO.

\begin{tabular}{cccccccc} 
& \multicolumn{2}{c}{} & \\
\hline & F1 & F3 & F5 & F7 & F9 & F10 & F11 \\
\hline PSO & $4.65 \mathrm{E}-17$ & $4.59 \mathrm{E}-15$ & $5.04 \mathrm{E}-07$ & $1.97 \mathrm{E}-04$ & $7.11 \mathrm{E}-15$ & $4.95 \mathrm{E}-09$ \\
\hline SSA & $6.94 \mathrm{E}-12$ & $7.92 \mathrm{E}-12$ & $1.70 \mathrm{E}-9$ & $9.57 \mathrm{E}-05$ & $3.14 \mathrm{E}-12$ & $1.26 \mathrm{E}-06$ & 0.0099 \\
\hline FPSO & $\mathbf{2 . 7 8 E}-45$ & $\mathbf{4 . 9 9 E}-47$ & $\mathbf{0}$ & $\mathbf{6 . 8 6 E - 0 5}$ & $\mathbf{0}$ & $\mathbf{8 . 8 8 E}-16$ & $\mathbf{0}$ \\
\hline
\end{tabular}

\begin{tabular}{rrrrccccc} 
& \multicolumn{1}{c}{ F } \\
\hline & F1 & F3 & F5 & F7 & F9 & F10 & F11 \\
\hline PSO & 40.5084 & 16.3141 & 8.2900 & 0.0191 & 0.4974 & 1.6649 & 0.1906 \\
\hline SSA & $\mathbf{7 . 2 9 1 9}$ & 5.0886 & 6.9000 & 0.0097 & 0.5130 & 1.3201 & 0.2107 \\
\hline FPSO & 8.7670 & $\mathbf{1 . 2 3 2 8}$ & $\mathbf{2 . 8 2 1 8}$ & $\mathbf{0 . 0 0 6 1}$ & $\mathbf{0 . 1 3 6 7}$ & $\mathbf{1 . 2 1 9 6}$ & $\mathbf{0 . 1 8 9 8}$
\end{tabular}

در جدول ب مقادير بهترين پِاسخ دست يافته در تعداد . ․ تكرار براى سه روش ذكر شده به صورت كمى ارائه شده است. جدول F مقدار انحر اف معيار را براى سه روش PSO و و FSA جدول مشاهده مى گردد كه الكوريتم SSA مقادير انحراف معيار كمترى

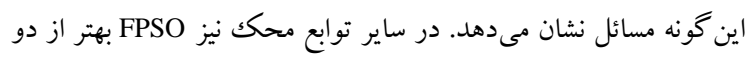

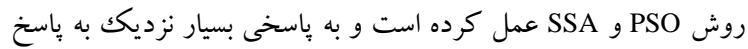
بهينه دست يافته است. 


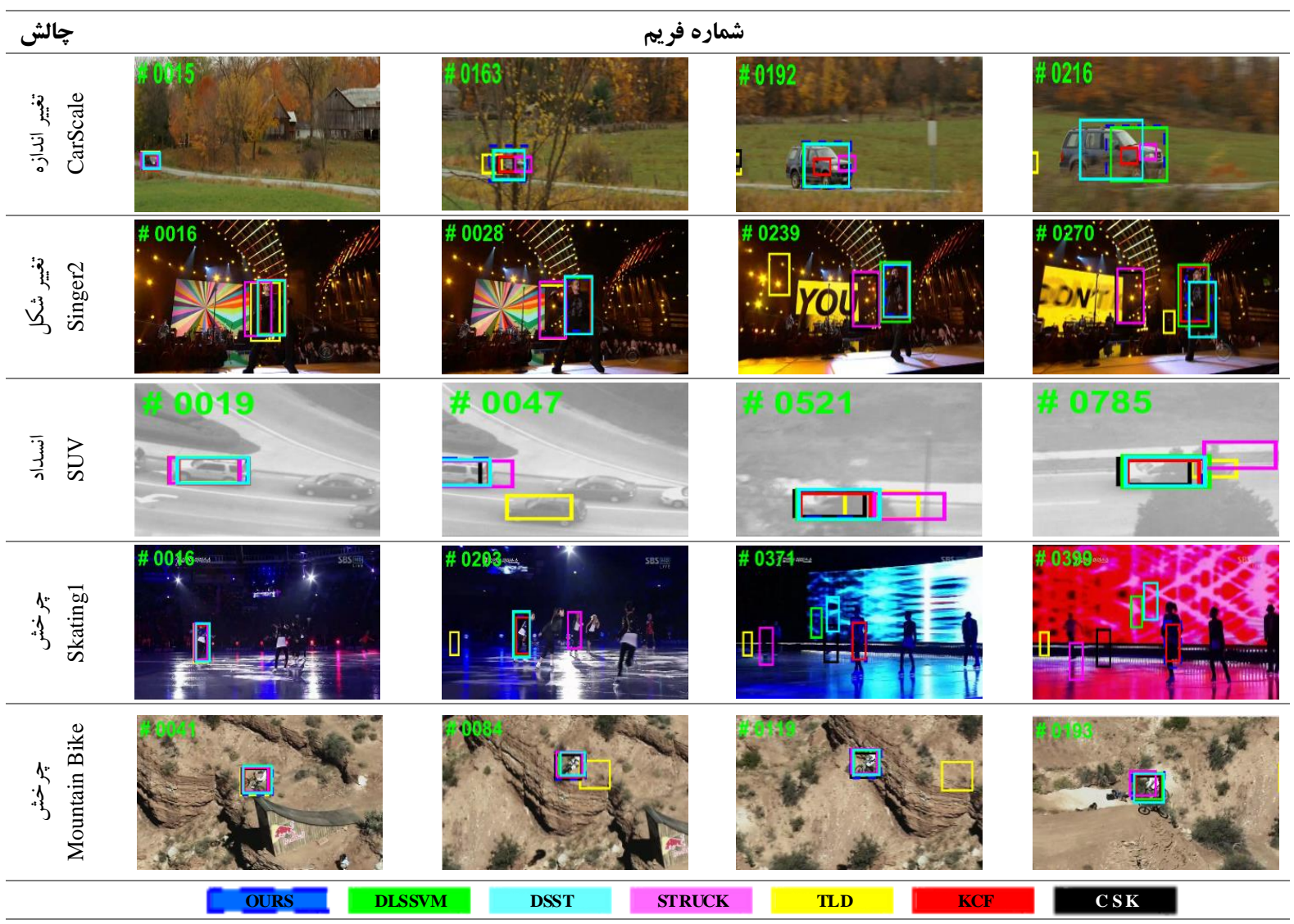

شكل ه: ارزيابى ه دنباله ويدئويى براى ₹ جالش تغيير اندازه، تغيير شكل، انسداد و جرخش با استفاده از روش FPSO و وروش مرسوم رديابى.

( •

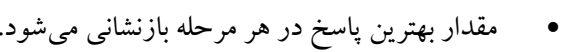
• • Popsize و مر هر مرحله بازنشانى

$$
\text { مىشوند. }
$$

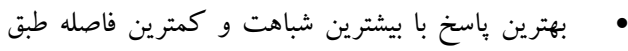

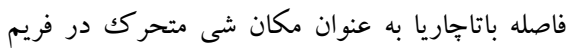

$$
\text { • }
$$

\section{OTB50 بإيكاه داده}

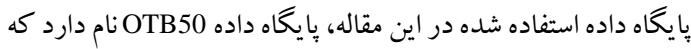

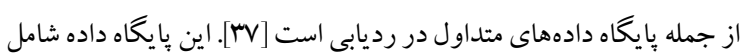

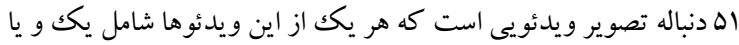

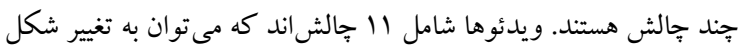

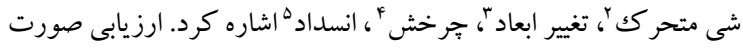

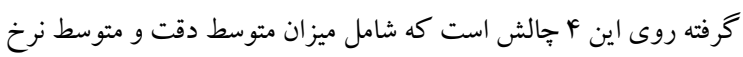

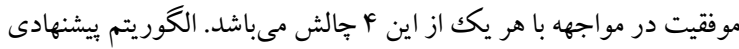

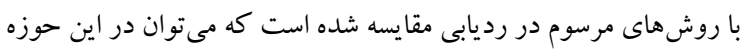

نسبت به روش PSO دارد به طورى كه در تابع محكك F1 داراى كمترين

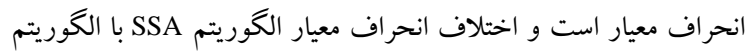

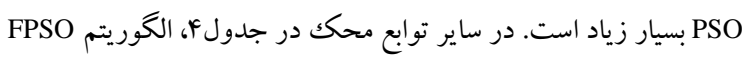

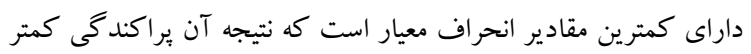

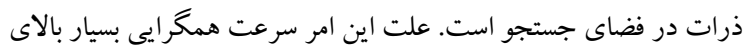

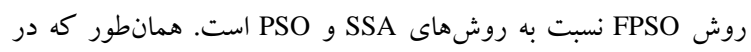
نمودارها مشخص است، شيب نمودارها براى الكوريتم FPSO بسيار زياد است كه نشان مى دهد سرعت همخر ايى بالاتر از دو الكوريتم ديخر است.

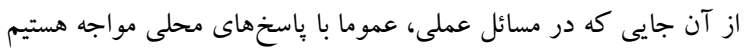

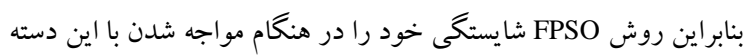
از مسائل نشان مى دهد. مراحل اجراى روش ييشنهادى به صورت زير است: • مقادير اوليه

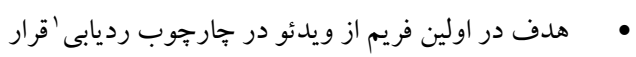
گيرد.

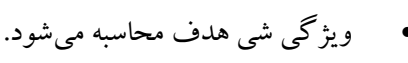

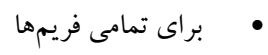

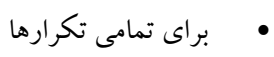

$\begin{array}{ll}{ }^{4} \text { Rotation } & { }^{1} \text { Bounding Box } \\ { }^{5} \text { Occlusion } & { }^{2} \text { Deformation } \\ & { }^{3} \text { Scale variation }\end{array}$


مهرداد روحانى، حسن فرسى، سيد حميد ظهيرى ممقانى

جدول ه: متوسط معيار دقت براى بايخاه داده OTB50

\begin{tabular}{|c|c|c|c|c|}
\hline نام روش & تغيير شكل & تغنيير & جرخش & انسداد \\
\hline $\operatorname{CSK}[6]$ & $r Q / \Lambda$. & rQ/Dr & $r F / \Gamma I$ & ו וT/M \\
\hline TLD [9] & $M F / D$. & $\mu F / \Delta$. & $r q / Y$. & rN/q. \\
\hline KCF [7] & FN/G. & $49 / 9$. & $\Delta F / q$. & $\Delta r / 9$. \\
\hline STRUCK [8] & $F \cdot / \Delta 1$ & $r q / r$. & 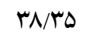 & $\mathrm{Mq/9T}$ \\
\hline DSST [10] & FN/A. & $F N / \cdots$ & $0 \cdot / 9$. & $\Delta V / \Delta$ \\
\hline DLSSVM [38] & $91 / 11$ & $\Delta 9 / 9$. & $01 / 9$. & $\tau \Lambda / r$. \\
\hline FPSO & $71 / 10$ & or/o. & $\tau \gamma / \cdot \varepsilon$ & $99 / 9$ \\
\hline
\end{tabular}

در جدول ه مقادير كمى براى روشهاى مختلف براى معيار دقت

نمايش داده شده است. از مقادير ثبت شده و مقايسه آنها مىتوان دريافت كه روش FPSO در جالشهاى تغيير اندازه و تغيير شكل توانسته است عملكرد بهترى را نسبت به ساير روشها به نما يش بخذارد درحالى كه روش

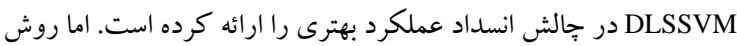
نيز مقدار نزديكك به مقدار روش DPSO نتايج جدول ه براى سطح آستانه خطاى بين صفر تا • ه ييكسل بررسى شده است. منظور از سطح آستانه خطا، اختلاف فاصلهى مكان مركز محاسبه شده و مركز واقعى هدف در يكك فريم است كه به كليهى فريمها تعميم داده شده و متوسط گيرى مىشود. مقدار گزارش شده سطح زير منحنى دقت براى سطح آستانه خطاى صفر تا •ه ي يكسل بر حسب درصد محاسبه

جدول 9: متوسط معيار نرخ موفقيت براى با يايخاه داده OTB50

\begin{tabular}{|c|c|c|c|c|}
\hline نام روش & شكيير & تغيير & هرخش & انسداد \\
\hline CSK [6] & $r \Delta / Y Y$ & YV/FY & rT/T & YF/VR \\
\hline TLD [9] & $Y \Lambda / Y$. & $r Y / 9$. & $r \wedge / \Delta$. & $\mathrm{rV} / \mathrm{I}$. \\
\hline KCF [7] & $\mathrm{rV} / \mathrm{q}$. & $M F / \mu$. & $F F / V$. & Fr/G. \\
\hline STRUCK [8] & $r r / l$. & Mr/91 & $r \cdot / \mu q$ & YN/9G \\
\hline DSST [10] & $r r / F$. & $\varepsilon 0 / 0$. & $F \cdot / \Lambda$. & Fr/g. \\
\hline DLSSVM [38] & $F r / q$. & $4 \cdot / \Delta$. & $F r / F$. & $\varepsilon V / 1$. \\
\hline FPSO & $\varepsilon \varepsilon / \Lambda$. & FF/AG & $\varepsilon \tau / 0$. & $\mathrm{FG/ \Lambda .}$ \\
\hline
\end{tabular}

جدول 4 نرخ موفقيت را به ازاى 4 روش مرسوم و روش FPSO در

معيار نرخ موفقيت نمايش مىدهد. از مقايسه نتايج به دست آمده مىتوان دريافت كه روش FPSO در جالش هاى تغيير شكل و جر خش توانسته است عملكرد بهترى را نسبت به ساير روش ها به نمايش بخذارد. روش KCF يس

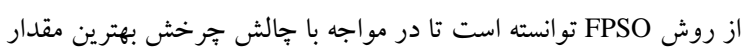
DLSSVM در جالش تغيير اندازه و روش DSST ركب كند. اما روش در جالش انسداد عملكرد بهترى را ارائه كردهاند. با اين حال روش FPSO مقادير نزديكك به اين دو روش را ثبت كرده است. مقادير گزارش شده سطح زير منحنى نرخ موفقيت براى سطح آستانه هميوشانى صفر تا ... درصد است. در سطح آستانه ... درصد نرخ موفقيت كليه روشها

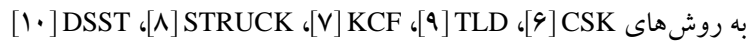

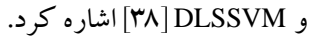

ارزيابى صورت گر فته در شكل ها براى روش FPSO و همجنين تعداد

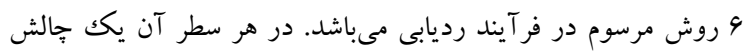

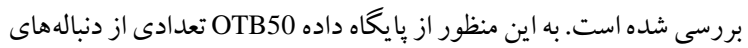

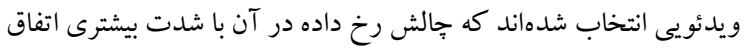

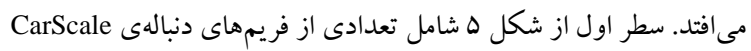
است. در اين دنباله تغييرات مقياس و يا اندازه در طول دنباله، به عنوان

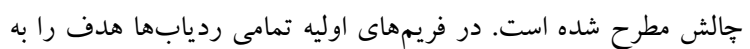

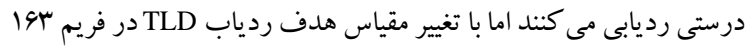

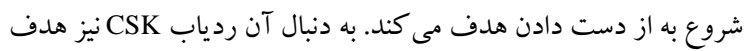
را از دست مىدهد. ساير رديابها از جمله ردياب FPSO قادرند تا هدف

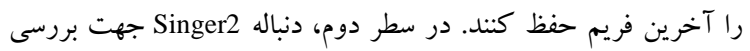

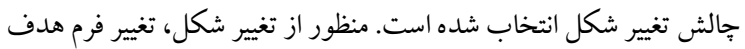

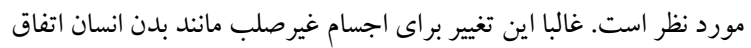

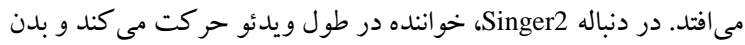

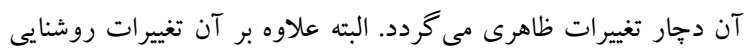

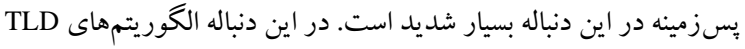

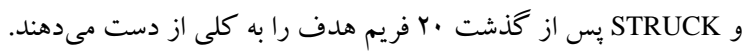

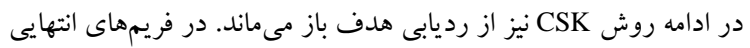

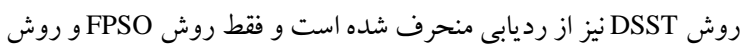

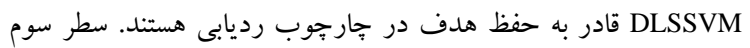
دربردارنده دنباله SVU است كه جهت بررسى جالش انسداد مطرح شده

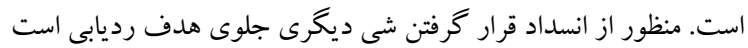

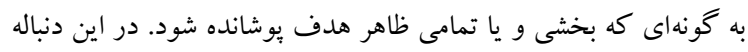

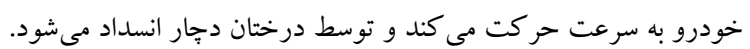
رديابهاى CSK TLD در اين دنباله قادر به رديابى هدف نيستند و هدف را در مواجه شدن با انسداد از دست مى دهند. سطر جهارم دنباله Skating را براى جالش جرخش هدف معرفى مى كند. در اين دنباله شخص با باله سرعت زياد حر كات نمايش شامل جرخش را انجام مى هدهد. در اين دنباله ردياب TLD و STRUCK هدف را در فريمهاى ابتدايى از دست مىدهند. اين در حالى است كه بس از كذشت .ها فريم رديابهاى DLSSVM، CSK و نSST

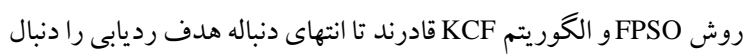

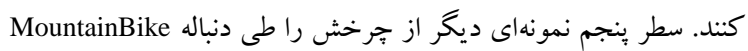

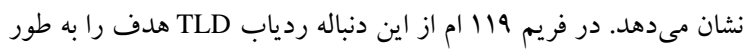

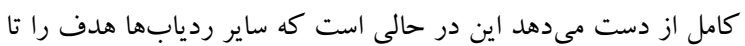
انتهاى ويدئو حفظ مى كنند. 


\section{مر اجع}

[1] M. Swathy, P. Nirmala and P. Geethu, "Survey on vehicle detection and tracking techniques in video surveillance", International Journal of Computer Applications, vol. 160, no. 7, pp. 22-28, 2017.

[2] I. Pham and M. Polasek, "Algorithm for military object detection using image data", IEEE/AIAA 33rd Digital Avionics Systems Conference (DASC), pp. 1-15, 2014.

[3] A. Yilmaz, O. Javed and M. Shah, "Object tracking: A survey”, Acm computing surveys (CSUR), vol. 38, no. 4, pp. 13-20, 2006.

[4] B. Zhuang, H. Lu, Z. Xiao, and D. Wang, "Visual tracking via discriminative sparse similarity map", IEEE Transactions on Image Processing, vol. 23, no. 4, pp. 1872-1881, 2014.

[5] H. Farsi, "Improvement of minimum tracking in minimum statistics noise estimation method", Signal Processing: An International Journal (SPIJ), vol. 4, no. 1, pp. 17-25, 2010.

[6] J. F. Henriques, R. Caseiro, P. Martins and J. Batista, "Exploiting the circulant structure of tracking-bydetection with kernels", European conference on computer vision, pp. 702-715, 2012.

[7] J. F. Henriques, R. Caseiro, P. Martins and J. Batista, "High-speed tracking with kernelized correlation filters", IEEE Transactions on pattern analysis and machine intelligence, vol. 37 , no. 3, pp. 583-596, 2015.

[8] S. Hare et al., "Struck: Structured output tracking with kernels", IEEE Transactions on pattern analysis and machine intelligence, vol. 38, no. 10, pp. 2096-2109, 2016.

[9] Z. Kalal, K. Mikolajczyk and J. Matas, "Trackinglearning-detection", IEEE Transactions on pattern analysis and machine intelligence, vol. 34, no. 7, pp. 1409-1422, 2012.

[0] M. Danelljan, G. Häger, F. S. Khan and M. Felsberg, "Discriminative scale space tracking," IEEE transactions on pattern analysis and machine intelligence, vol. 39, no. 8, pp. 1561-1575, 2017.

[1] K. Zhang, L. Zhang, Q. Liu, D. Zhang and M. Yang, "Fast visual tracking via dense spatio-temporal context learning", European conference on computer vision, pp. 127-141, 2014.

[2] D. S .Bolme, J. R. Beveridge, B. A. Draper and Y. M. Lui, "Visual object tracking using adaptive correlation filters", IEEE Conference on Computer Vision and Pattern Recognition (CVPR), pp. 2544-2550, 2010.

[3] M. Danelljan, G. Häger, F. Khan and M. Felsberg, "Accurate scale estimation for robust visual tracking", British Machine Vision Conference, pp. 1-5, 2014.

[4] M. Gao, X. He, D. Luo, J. Jiang and Q. Teng, "Object tracking using firefly algorithm", IET Computer Vision, vol. 7, no. 4, pp. 227-237, 2013.

[5] N. Hussain, A. Khan, S. G. Javed and M. Hussain, "Particle swarm optimization based object tracking using HOG features", IEEE 9th International
نزديك به صفر شده و در سطح آستانهاى نزديكك به صفر نرخ موفقيت

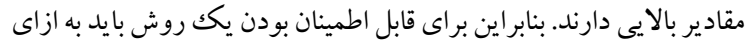

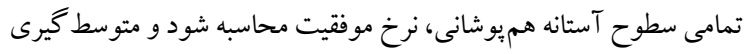

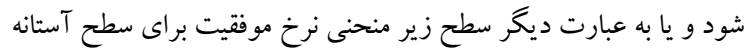
هميوشانى صفرتا .. إدرصد محاسبه شود.

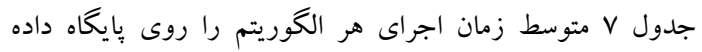

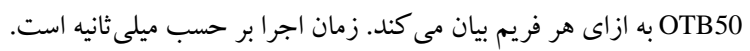
در اين جدول مشاهده مىشود كه روش CSK داراى كمترين زمان اجرا

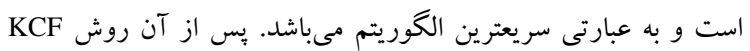

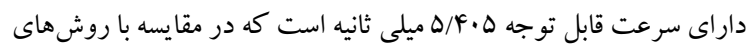

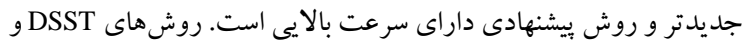

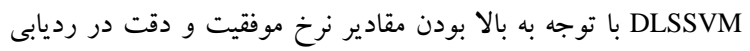

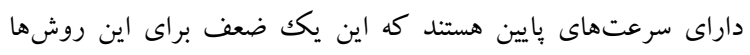

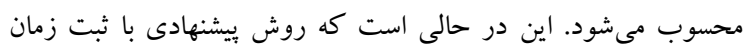

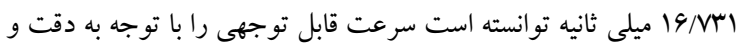
نرخ موفقيت بالاى خود كسب كند. r-ع- نتيجه كيرى و ويشنهادات

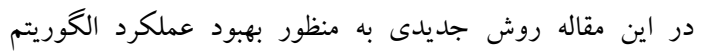

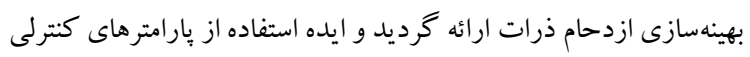

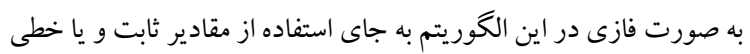

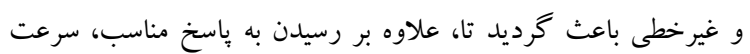

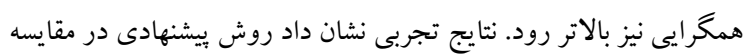

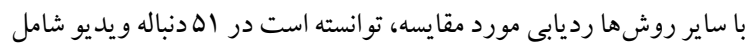

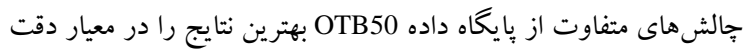

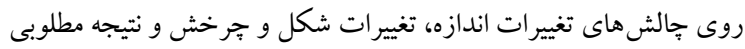

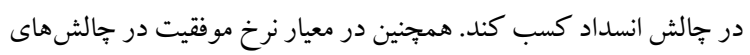
جرخش و تغيير شكل بهترين نتايج و در حالت تغيير اندازه و انسداد نيز

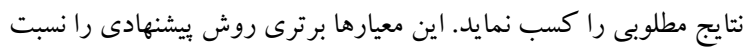

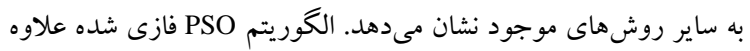

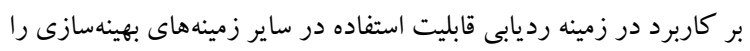

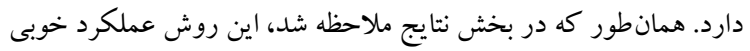

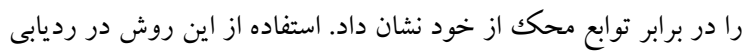

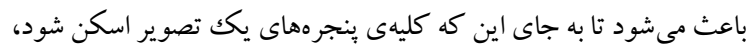

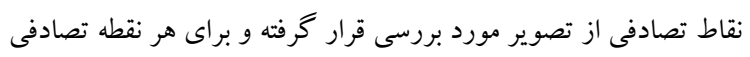

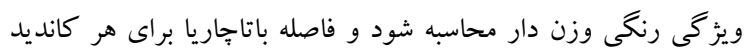

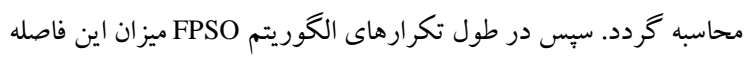
به حداقل برسد و مكان هدف در هر فريم با دقت مطلوبى شناسايى گرددد.

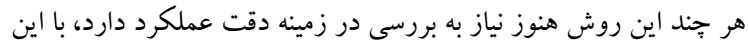

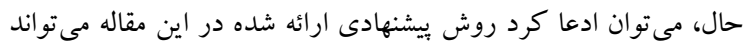

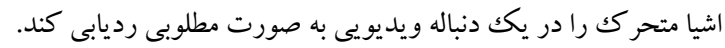


in optimization of fuzzy controllers", Algorithms, vol. 10, no. 3, p. 101-128, 2017.

[30] F. Valdez, J. C. Vazquez and F. Gaxiola, "Fuzzy dynamic parameter adaptation in ACO and PSO for designing fuzzy controllers: the cases of water level and temperature control", Advances in Fuzzy Systems, vol. 2018, no. 1, pp. 1-19, 2018.

[31] B. Borowska, "Nonlinear inertia weight in particle swarm optimization", 12th International Scientific and Technical Conference on Computer Sciences and Information Technologies (CSIT), vol. 1 ,pp. 296-299, 2017.

[32] C. Du, Z .Yin, Y. Zhang, J. Liu, X. Sun and Y. Zhong, "Research on active disturbance rejection control with parameter autotune mechanism for induction motors based on adaptive particle swarm optimization algorithm with dynamic inertia weight", IEEE Transactions on Power Electronics, vol. 34, no. 3, pp. 2841-2855, 2019.

[33] M. Swain and D. Ballard, "Color indexing", Computer Vision, vol. 7, no. 1, pp. 11-32, 1991

[34] D. Zhang, J. Zhang and C. Xia, "Multi-complementary model for long-term tracking", Sensors, vol. 18, no. 2 , pp. 527-552, 2018.

[35] L. Luo and X. Fan, "Immune particle filter algorithm for target tracking based on histograms of color and oriented gradient", Optical Sensing and Imaging Technology and Applications, vol. 10462, pp. 104622Q, 2017.

[36] A. Sharma, A. Malik and R. Rohilla, "A robust mean shift integrating color, GLCM based texture features and frame differencing", International Journal of Scientific and Engineering Research, vol. 7, no. 2, pp. 1386-1398, 2016.

[37] Y. Wu, J. Lim and M. Yang, "Online object tracking: A benchmark", IEEE Computer vision and pattern recognition (CVPR), pp. 2411-2418, 2013.

[38] J. Ning, J. Yang, S. Jiang, L. Zhang and M. Yang, "Object tracking via dual linear structured SVM and explicit feature map", Proceedings of the IEEE conference on computer vision and pattern recognition, pp. 4266-4274, 2016
Conference on Emerging Technologies (ICET), pp. 16, 2013.

[6] F. Sha, C. Bae, G. Liu, X. Zhao, Y. Chung and W. Yeh, "A categorized particle swarm optimization for object tracking", IEEE Congress on Evolutionary Computation (CEC), pp. 2737-2744, 2015.

[7] C .Bae, K. Kang, G. Liu and Y. Chung, "A novel real time video tracking framework using adaptive discrete swarm optimization", Expert Systems with Applications, vol. 64, no. 1, pp. 385-399, 2016.

[8] J. Kennedy, "Particle swarm optimization", Encyclopedia of machine learning, pp. 760-766, 2010.

[9] S. Mirjalili, A. Gandomi, S. Z. Mirjalili, S. Saremi, H. Faris and S. M. Mirjalili, "Salp Swarm Algorithm: A bio-inspired optimizer for engineering design problems", Advances in Engineering Software, vol. 114, pp. 163-191, 2017.

[20] S. Mirjalili and A. Lewis, "The whale optimization algorithm", Advances in engineering software, vol. 95, pp. 51-67, 2016.

[21] S. Mirjalili, "SCA: a sine cosine algorithm for solving optimization problems", Knowledge-Based Systems, vol. 96, pp. 120-133, 2016.

[22] J. Kennedy and R. Eberhart, "Particle swarm optimization (PSO)", IEEE International Conference on Neural Networks, Perth, Australia, pp. 1942-1948, 1995.

[23] Y. Shi and R. Eberhart, "A modified particle swarm optimizer", IEEE international conference on evolutionary computation proceedings world congress on computational intelligence (Cat. No. 98TH8360), pp. 69-73, 1998.

[24] A. Chatterjee and P. Siarry, "Nonlinear inertia weight variation for dynamic adaptation in particle swarm optimization", Computers and operations research, vol. 33 , no. 3 , pp. 859-871, 2006

[25] H. Zhu, C. Zheng, X. Hu and X. Li, "Adaptive PSO using random inertia weight and its application in UAV path planning", Seventh International Symposium on Instrumentation and Control Technology: Measurement Theory and Systems and Aeronautical Equipment, vol. 7128, p. 712814712819, 2008.

[26] T. Niknam, "A new fuzzy adaptive hybrid particle swarm optimization algorithm for non-linear, nonsmooth and non-convex economic dispatch problem", Applied Energy, vol. 87, no. 1, pp. 327-339, 2010.

[27] Y. Maldonado, O. Castillo and P. Melin, "Particle swarm optimization of interval type-2 fuzzy systems for FPGA applications", Applied Soft Computing, vol. 13, no. 1, pp. 496-508, 2013

[28] T. Krzeszowski and K. Wiktorowicz, "Evaluation of selected fuzzy particle swarm optimization algorithms", Federated Conference on Computer Science and Information Systems (FedCSIS), pp. 571575,2016

[29] F. Olivas, L. Amador-Angulo, J. Perez, C. Caraveo, F. Valdez and O. Castillo, "Comparative study of type-2 fuzzy particle swarm, bee colony and bat algorithms 